\title{
Prediction of infant hospital admission risk
}

\author{
T R CULLINAN AND D I SAUNDERS
} Department of Environmental and Preventive Medicine, St Bartholomew's Hospital Medical College and the
Department of Computer Science and Statistics, Queen Mary College, London

SUMMARY Data on health status and various socioeconomic and dietary factors were obtained for every infant born during a 1 year period in east London. A simple scoring system was developed to predict the risk of hospital admission.

A survey was carried out of infants born between March 1979 and February 1980 in two districts (Tower Hamlets, and City and Hackney) of east London. Health visitors from both districts paid visits to the homes of as many babies as possible at about 4 weeks after birth and made detailed notes of home and family circumstances, health status, exposure to indoor pollution, weight, medication, and feeding practices. Observations were based on a questionnaire derived from Professor Emery's work in Sheffield. ${ }^{1}$ After the first 6 months the questionnaire was modified slightly and a revised questionnaire (questionnaire B) was used for the next 6 months. A preliminary analysis was performed and details reported by Cullinan and Treuherz. ${ }^{2}$ Roughly $85 \%$ (actually 3711 ) of the babies born and resident in the districts at age 4 weeks were included in this initial phase of the study, as some babies were still in hospital and there were staffing difficulties. Between March 1979 and January 1981 the admissions records at each of the four hospitals in east London admitting infants were checked for any baby in the original cohort who had been admitted to hospital for any reason and details of the admission were recorded. The distribution of illness in subgroups of the sample and the relationship between various factors, reported symptoms of illness, and actual hospital admission have been examined further. ${ }^{3} 417$

\section{Statistical methods used for predicting admission risk}

While most epidemiological studies are concerned with factors that directly affect the incidence of disease or at least hospital admission or some other related variable, it is sometimes useful to be able to predict levels of incidence or admission in certain areas or equivalently to predict degrees of risk for individuals within those areas, and models used for such purposes would also include factors that are not directly causal.

Various statistical techniques have been used for this purpose. Feldstein ${ }^{5-7}$ used weighted linear regression to predict mortality rates from social class, parity, and age by regressing the mortality rates directly on dichotomous dummy variables corresponding to the various factor levels. The interaction terms were found to be negligible in that study and not worth the increased complexity required to include them. The rates in their analysis lay between about $2 \%$ and $10 \%$ for the various subgroups and over this range the curvature of the response surface would be only slight.

The same technique was used by Winter and Lilos. ${ }^{8}$ Their interest was, however, in admissions to hospital in the first 2 years of life and their subgroup admission rates were much more varied. Their predicted admission rates varied from $-8 \%$ to $54 \%$ as their model did not force the rates to be positive. The non-additivity of factors were expressed as significant interactions between independent factors. The authors commented that 'multivariate analysis showed that many group factors are interrelated and therefore inconsistent', they then ignored these factors or the corresponding interactions.

In a study of infant deaths in Sheffield, Carpenter et $a .^{9-11}$ used stepwise discriminant analysis to distinguish between levels of risk of unexpected death of infants. A linear combination of variables-such as mother's age, number of previous pregnancies-was given a score which was then used to identify high and low risk categories. Interaction between variables was assumed to be neglible. Each infant was given a preliminary score at birth and then an amended multistage score after a month. Infants scoring above the estimated 85th centile were designated high risk. ${ }^{9}$ For such a technique the variable coefficients are dependent not only on the effectiveness of the variable as a predictor but also on the proportion of the population in each combination of factor levels and hence lose some of their validity if the population characteristics change. The scoring system was tested on a separate sample from 
that used to derive the coefficients ${ }^{10}$ and shown to be effective as a discriminator, though with some apparent reduction in performance. While the discriminant function is linear the resultant risk is a nonlinear function of the scores. Hence the score has to be transformed to obtain an estimated quantified risk of admission. Carpenter ${ }^{12}$ showed that scoring system estimates obtained from discriminant analysis will be directly proportional to those obtained from logistic regression. In the following this logit model is used as it enables us directly to relate the risk of admission to a linear combination of factor values-that is risk of admission $=\exp ($ linear model $) /\{1+\exp ($ linear model $)\}$. This may be rewritten as

$$
\ln (p /(1-p))=\text { linear model }
$$

This ensures that the probabilities predicted remain between 0 and 1 . Further explanation of this model may be found in many texts. ${ }^{13-15}$ This model is used below and is shown to fit the data well with none of the interaction trouble found by Winter and Lilos. ${ }^{8}$

\section{Prediction of admission risk using the logit model}

A simple additive formula for predicting the risk of admission was obtained, with emphasis on prediction rather than causality.

To calculate the risk add the appropriate values from Table 1. The score obtained will lie between 0 and 25 with a high value indicating a high risk. The actual predicted risk may be calculated using the formula in the last section with the linear model being $-2 \cdot 84+$ score $/ 10$. These risk values are listed in Table 2. Thus for a 'not well' non-Asian baby of normal weight whose mother had good assessments but did not breast feed at all with the father's occupation being 'high', the simplified score from Table 1 is 14 which has a predicted risk of 0.19 -that is atout a $20 \%$ chance of admission.

Variables known to be individually good predictors of whether the baby will be admitted are described in more detail below and include: (1) to (4) The health visitor's assessment of the mother's feeding habits, hygiene, relationship with the baby, and her 'acceptable norm'. (5) Method of feeding. (6) Father's occupation. (7) Whether the baby was well when 4 weeks old. (8) Smoking within the household. (9) Birthweight of the baby. (10) Race of the child.

By controlling individually for variables (5) to (10) these ten were also seen to be good predictors in their own right. It was thought that housing standards could be important, in particular the number of rooms and the provision of various facilities-such as running water, kitchen sinks, and lavatories, and whether these were separate or
Table 1 Simplified scores for predictive factors

\begin{tabular}{ll}
\hline Addition & When added \\
\hline 2 & If assessment of feeding is 'not good' \\
4 & If assessment of relationship with baby is 'not good' \\
4 & If there is no breast feeding \\
3 & If the father's occupation category is 'low' \\
2 & If birthweight is less than $2500 \mathrm{~g}$ \\
10 & If the baby is non-Asian and is classed as 'not well' \\
1 & If the baby is Asian \\
9 & Extra if the baby is Asian and has birthweight less \\
& than $2500 \mathrm{~g}$ \\
\hline
\end{tabular}

Table 2 Predicted risks of admission for all possible scores

\begin{tabular}{llll}
\hline Score & Admitted $(\%)$ & Score & Admitted $(\%)$ \\
\hline 0 & 6 & 13 & 18 \\
1 & 6 & 14 & 19 \\
2 & 7 & 15 & 21 \\
3 & 7 & 16 & 22 \\
4 & 8 & 17 & 24 \\
5 & 9 & 18 & 26 \\
6 & 10 & 19 & 28 \\
7 & 11 & 20 & 30 \\
8 & 12 & 21 & 32 \\
9 & 13 & 22 & 35 \\
10 & 14 & 23 & 37 \\
11 & 15 & 24 & 39 \\
12 & 16 & 25 & 42 \\
\hline
\end{tabular}

shared. Owing to a large degree of confounding with other variables and the high admission rates from minimal but sufficient housing-that is with 3 or 4 rooms and separate inside lavatory-the best housing predictor was whether the household was a shared one.

There was a high degree of correlation between the health visitor's assessments listed as variables (1) to (4) above; for instance a breast feeding mother would be deemed to have better feeding habits and also a better relationship with the baby. 'Feeding habits' also included whether the mix had been prepared correctly for bottle-fed babies. The last of the four, namely assessment of the mother's acceptable norm, was excluded as it was the least significant and would be covered by the other three. These assessments had been coded by the health visitors as good, fair, poor, and very poor but, as the last two categories had proportionally few responses and did not seem to correspond to much higher levels of admission, were recategorised with fair into not good. An analysis similar to that described below was done with variables (1) to (4) and 'baby not well'-that is variable (7). This indicated that not only could the health visitor's assessment of the mother's acceptable norm be dropped but so could the assessment of her level of hygiene. However hygiene was retained temporarily because of its obvious importance.

As is discussed elsewhere,${ }^{4}$ the method of feeding may be dichotomised without loss into whether or not the baby receives some breast feeding. 
For the sake of simplicity 'father's occupation' was dichotomised into 'high' (class I, II, or III non-manual) and 'low' (III manual, IV, V, unemployed, student, unknown, member of the armed forces). This variable was chosen to provide some measure of socioeconomic status.

Smoking within the household was regarded as 'heavy' if anyone in the household' smoked more than 10 cigarettes a day or if both the mother and someone else smoked. Otherwise it was regarded as 'light'.

Birthweight was dichotomised into below $2500 \mathrm{~g}$ and at least $2500 \mathrm{~g}$.

The admission rate for Asians was high for all main causes, whereas the other minorities seemed to have roughly the same admission rate as those categorised as Caucasian. Race was therefore categorised as 'Asian' or 'Other'. The causes of high Asian morbidity are described elsewhere ${ }^{3}{ }^{4}$ and race in the predictive sense used here is mainly in connection with low birthweight.

We thus have 10 dichotomous variables with which to predict a risk of admission. A modified form of the stepwise forward selection method proposed by Goodman ${ }^{16}$ was used to choose the terms of the linear model.

The only significant interaction terms were those between race and the variables 'baby not well' and 'birthweight'. The former was not a good predictor for Asians but was an excellent predictor for the rest. 'Birthweight', however, was a much better predictor for the Asians. No second order interaction terms were significant. The variables representing the health visitor's assessment of the mother's hygiene and shared housing contributed very little to the model ( $\chi^{2}$ of 0.2 on 2 degrees of freedom for the deviance difference) and were consequently not used. Smoking habits were also covered by other variables $\left(\chi^{2}\right.$ of 0.6 on 1 degree of freedom for inclusion/exclusion of the smoking factor if the model included the two interaction terms but not the other two factors mentioned above).

The health visitor's assessment of the mother's feeding methods is not quite statistically significant in that the information it carries is covered partly by the actual feeding method and partly by the health visitor's assessment of the mother's relationship with the baby. Nevertheless it was felt that its inclusion would lead to a predictor that would be reliable as it would work in all areas and not just in the sample as a whole.

The linear model is a mean term of $-2 \cdot 841$, corresponding to a predicted admission rate of $5.5 \%$, with quantities added as in Table 3 .

For example, for a 'not well' non-Asian baby of normal weight whose mother had good assessments
Table 3 Scores for predictive factors

\begin{tabular}{ll}
\hline Addition & When added \\
\hline 0.199 & If assessment of feeding is 'not good' \\
0.385 & If assessment of relationship with baby is 'not good' \\
0.402 & If there is no breast feeding \\
0.264 & If the father's occupation category is 'low' \\
0.150 & If birthweight is less than $2500 \mathrm{~g}$ \\
0.984 & If the baby is non-Asian and is classed as 'not well' \\
0.106 & If the baby is Asian \\
0.960 & Extra if the baby is Asian and has birthweight less \\
& than $2500 \mathrm{~g}$ \\
\hline
\end{tabular}

but did not breast feed at all with the father's occupation being 'high', the score is $-2.841+0.402$ $+0.984=-1.454$ and the predicted risk of admission is $\exp (-1.454) /\{1+\exp (-1.454)\}=0.189$ -that is about a $20 \%$ chance.

The above may be simplified without losing much predictive ability (the difference in models gives a $\chi^{2}$ value of $0 \cdot 1$ on 1 degree of freedom) by ignoring the $-2 \cdot 841$ and converting the other numbers to convenient integers. This gives the simplified score mentioned at the start of this section. This has a base value of 0 with the additions as in Table 1 .

The worst that anyone can score on this scale is 25 which corresponds to a predicted chance of admission of roughly $40 \%$.

Table 4 gives details of the distribution of scores grouped to show the range of scores for the $1 \%$ with the highest-that is worst scores, the worst $5 \%$, $10 \%$, and $50 \%$ of the population, and the $50 \%$ who have the lowest scores. The last column shows that there is an overall admission rate of roughly 1 in 10 . However, babies scoring at least 13 have an admission rate double this $(21.9 \%)$. From the second column roughly $10 \%$ of babies have a score of at least $13(5 \cdot 6+4 \cdot 1+1 \cdot 1)$.

Table 5 compares the actual number admitted for each of the categories used above with the number of admissions predicted by the simplified model. The predicted number for each category was obtained by multiplying the number with each score by the predicted admission rate for that score and summing over the scores in the category.

The number of infants in the first 6 months (using questionnaire A) was roughly equal to the number born in the second 6 months (using the

\begin{tabular}{|c|c|c|c|c|}
\hline \multirow[t]{2}{*}{ Score } & \multicolumn{2}{|l|}{ Percentage } & \multirow{2}{*}{$\begin{array}{l}\text { Number with } \\
\text { this score } \\
\text { or worse }\end{array}$} & \multirow{2}{*}{$\begin{array}{l}\text { Admitted } \\
(\%)\end{array}$} \\
\hline & $\begin{array}{l}\text { Of population } \\
\text { with this score }\end{array}$ & $\begin{array}{l}\text { Of those } \\
\text { admitted }\end{array}$ & & \\
\hline $\begin{array}{c}>20 \\
15-20 \\
13,14 \\
7-12 \\
0-6\end{array}$ & $\begin{array}{r}1 \cdot 1 \\
4 \cdot 1 \\
5 \cdot 6 \\
38 \cdot 0 \\
51 \cdot 1\end{array}$ & $\begin{array}{r}42 \cdot 9 \\
23 \cdot 7 \\
16 \cdot 3 \\
11 \cdot 4 \\
7 \cdot 9\end{array}$ & $\begin{array}{r}42 \\
194 \\
402 \\
1813 \\
3711\end{array}$ & $\begin{array}{l}42 \cdot 9 \\
27 \cdot 8 \\
21 \cdot 9 \\
13 \cdot 7 \\
10 \cdot 8\end{array}$ \\
\hline
\end{tabular}


Table 5 Comparison of actual and predicted admissions

\begin{tabular}{lccc}
\hline Score & $\begin{array}{l}\text { Number with } \\
\text { this score }\end{array}$ & $\begin{array}{l}\text { Number } \\
\text { admitted }\end{array}$ & $\begin{array}{l}\text { Predicted number } \\
\text { of admissions }\end{array}$ \\
\hline$>20$ & 42 & 18 & 14 \\
$15-20$ & 152 & 36 & 37 \\
13.14 & 208 & 34 & 38 \\
$7-12$ & 1411 & 161 & 167 \\
$0-6$ & 1898 & 150 & 138 \\
\hline
\end{tabular}

almost identical questionnaire B). This then forms a convenient division for testing the reliability of the scoring system. The admission percentages are given in Table 6. For each of the two groups those scoring at least $15 \mathrm{had}$ an admission rate three times that of those scoring 0 to 6 and for each of the two groups roughly $5 \%$ and $50 \%$ respectively lay in these ranges. Thus the scores and the reliability of the scale as a predictor remained fairly constant.

Other groupings may be chosen if a proportion of the population other than $1,5,10$, or $50 \%$, or a more equal grouping of scores, is required. Table 7 gives the actual and predicted admission rates for any cause for the grouping $0-6,7-12,13-18,19-25$. The admission rate for a score of at least 19 may be seen to be roughly $30 \%$, and slightly fewer than $1 \%$ of the population are in this category. The corresponding rates for gastrointestinal infection and respiratory tract infection separately are given in Table 8 and these indicate that the same scoring system may be used to find most infants with a high risk of admission for these particular causes.

The Figure illustrates the relationships between score and actual admission rates (A) for any causes, (G) for gastrointestinal infection, (R) for respiratory tract infection, and (P) for predicted overall risk of admission for each of the four groups mentioned above. These are plotted at the midpoint of the score interval they represent. It can be seen that the actual and predicted rates are almost coincident.

The effect of a policy of declaring any infant scoring more than 12 'at risk' may partly be found from Table 9. There are roughly equal numbers of infants falsely declared to be 'not at risk' and 'at risk'. Only $9.4 \%$ (311 out of 3309) of those who would have been declared 'not at risk' were admitted and allowing the health workers more

Table 6 Comparison of scores and admission rates for two subsamples

\begin{tabular}{|c|c|c|c|c|}
\hline \multirow[t]{2}{*}{ Score } & \multicolumn{2}{|l|}{ Percentage } & \multicolumn{2}{|l|}{ Percentage } \\
\hline & $\begin{array}{l}\text { Of As with } \\
\text { this score }\end{array}$ & $\begin{array}{l}\text { Of those } \\
\text { admitted }\end{array}$ & $\begin{array}{l}\text { Of Bs with } \\
\text { this score }\end{array}$ & $\begin{array}{l}\text { Of those } \\
\text { admitted }\end{array}$ \\
\hline $\begin{array}{c}>20 \\
15-20 \\
13,14 \\
7-12 \\
0-6\end{array}$ & $\begin{array}{r}0.6 \\
4.4 \\
6 \cdot 2 \\
38 \cdot 6 \\
50 \cdot 3\end{array}$ & $\begin{array}{r}27 \cdot 3 \\
21 \cdot 3 \\
17 \cdot 7 \\
11 \cdot 2 \\
6 \cdot 4\end{array}$ & $\begin{array}{r}1 \cdot 6 \\
3 \cdot 8 \\
5 \cdot 1 \\
37 \cdot 5 \\
52 \cdot 0\end{array}$ & $\begin{array}{r}48 \cdot 4 \\
26 \cdot 4 \\
14 \cdot 7 \\
11 \cdot 6 \\
9 \cdot 3\end{array}$ \\
\hline
\end{tabular}

Table 7 Comparison of admission rates for equally sized score intervals

\begin{tabular}{|c|c|c|c|c|c|c|}
\hline \multirow[t]{2}{*}{ Score } & \multirow{2}{*}{$\begin{array}{l}\text { Number } \\
\text { in } \\
\text { cohort }\end{array}$} & \multirow{2}{*}{$\begin{array}{l}\% \text { of } \\
\text { cohort }\end{array}$} & \multirow{2}{*}{$\begin{array}{l}\text { Number } \\
\text { admitted }\end{array}$} & \multirow{2}{*}{$\begin{array}{l}\text { As } \% \text { of } \\
\text { population }\end{array}$} & \multicolumn{2}{|c|}{ Admission } \\
\hline & & & & & Actual & Predicted \\
\hline $\begin{array}{c}0-6 \\
7-12 \\
13-18 \\
19-25\end{array}$ & $\begin{array}{r}1898 \\
1411 \\
326 \\
76\end{array}$ & $\begin{array}{r}51 \cdot 1 \\
38 \cdot 0 \\
8 \cdot 8 \\
2 \cdot 0\end{array}$ & $\begin{array}{r}150 \\
161 \\
64 \\
24\end{array}$ & $\begin{array}{l}4 \cdot 0 \\
4 \cdot 3 \\
1 \cdot 7 \\
0 \cdot 7\end{array}$ & $\begin{array}{r}7.9 \\
11.4 \\
19.6 \\
31.6\end{array}$ & $\begin{array}{r}7 \cdot 5 \\
13 \cdot 1 \\
21 \cdot 6 \\
33 \cdot 4\end{array}$ \\
\hline
\end{tabular}

Table 8 Admission rates for gastrointestinal and respiratory tract infection

\begin{tabular}{|c|c|c|c|c|}
\hline \multirow[t]{2}{*}{ Score } & \multicolumn{2}{|c|}{ Respiratory tract } & \multicolumn{2}{|c|}{ Gastrointestinal } \\
\hline & $\begin{array}{l}\text { Number } \\
\text { admitted }\end{array}$ & $\begin{array}{l}\text { Admission } \\
\text { rate }\end{array}$ & $\begin{array}{l}\text { Number } \\
\text { admitted }\end{array}$ & $\begin{array}{l}\text { Admission } \\
\text { rate }\end{array}$ \\
\hline $\begin{array}{c}0-6 \\
7-12 \\
13-18 \\
19-25\end{array}$ & $\begin{array}{r}47 \\
52 \\
13 \\
7\end{array}$ & $\begin{array}{l}2 \cdot 5 \\
3 \cdot 7 \\
4 \cdot 0 \\
9 \cdot 2\end{array}$ & $\begin{array}{r}26 \\
40 \\
13 \\
8\end{array}$ & $\begin{array}{r}1 \cdot 4 \\
2.8 \\
4 \cdot 0 \\
10 \cdot 5\end{array}$ \\
\hline
\end{tabular}

Table 9 Effect of dichotomising into 'at risk' (score more than 12) and 'not at risk' (score not more than 12)

\begin{tabular}{lrrr}
\hline Score and decision & \multicolumn{3}{l}{ Whether admitted for any cause } \\
\cline { 2 - 3 } & Not admitted & Admitted & Total \\
\hline Not more than 12, 'not at risk' & 2998 & 311 & 3309 \\
More than 12, 'at risk' & 314 & 88 & 402 \\
Total & 3312 & 399 & 3711 \\
\hline
\end{tabular}

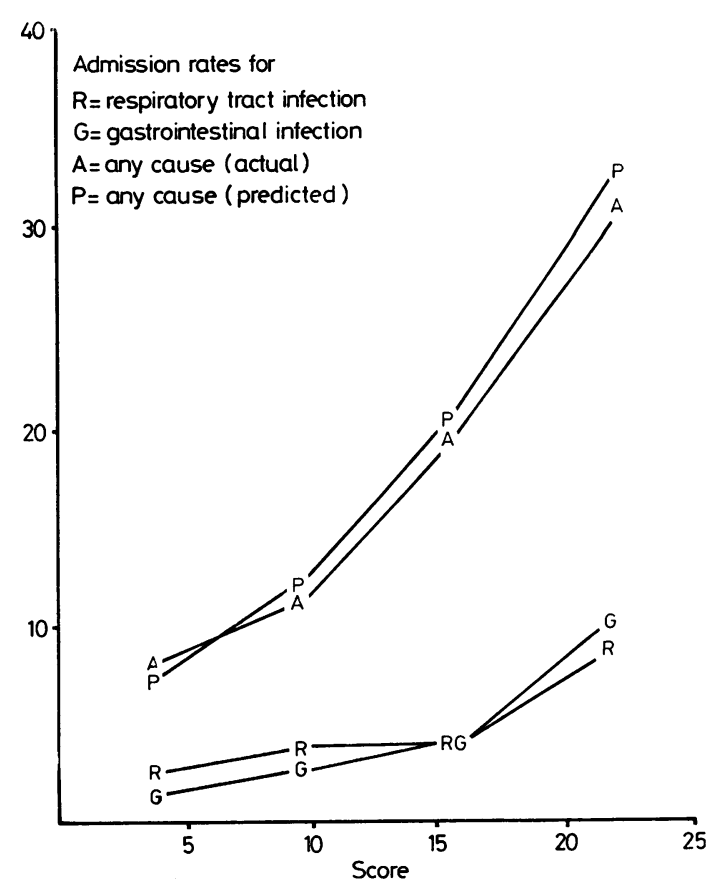

Fig. 1 Relation between admission rates and score. 
discretion in whether to categorise an infant as 'at risk' would undoubtedly pick up many of these as their judgement of the home situation is strongly correlated with whether a child is admitted. It would fairly certainly be beneficial if extra attention was given to all 'at risk' infants, even to children who would not have been admitted $(78 \%$ of those declared 'not at risk') and also to other younger infants in the same family and hence would not be wasted.

Scales were developed using only factors known at birth. These were not as discriminatory nor as reliable as the scale described above. The technique outlined above may also be used for deriving simple predictor formulae for specific causes of admission.

\section{Relative risk}

The risk of admission associated with the presence of a risk factor relative to its absence depends on the values of the other factors in the model. This is also true for the models of Feldstein and Carpenter mentioned earlier. For a given individual the risk with and without the particular factor could be calculated and the relative risk obtained therefrom. In the example used earlier, if the mother had breast fed the score would have been $-2.841+0.984=-1.857$ with predicted risk 0.135 and thus not breast feeding had a relative risk in that case of $0 \cdot 189 / 0 \cdot 135$ $=1.4$-that is a $40 \%$ increase of risk.

Note, however, that the predicted relative risk for a particular factor is maximum if no other risk factors pertain to that individual and decreases as other risk factors are known to contribute to that individual's risk. Consequently we can obtain an indication of the range of relative risk for a factor by evaluating it when no other risk factor is present and when all are. This is done in Tables 10 and 11 separately for Asians and non-Asians because of the complicating interactions between race, birthweight, and 'baby not well'. For Asians the minimum

Table 10 Relative risks of predictive factors for Asians

\begin{tabular}{ll}
\hline Factor & Range of relative risk \\
\hline Assessment of feeding 'not good' & $1 \cdot 13-1 \cdot 20$ \\
Assessment of relationship 'not good' & $1 \cdot 28-1 \cdot 43$ \\
No breast feeding & $1 \cdot 29-1 \cdot 45$ \\
Father's occupation category 'low' & $1 \cdot 18-1 \cdot 30$ \\
Birthweight less than $2500 \mathrm{~g}$ & $2 \cdot 21-2 \cdot 98$ \\
\hline
\end{tabular}

Table 11 Relative risks of predictive factors for non-Asians

\begin{tabular}{ll}
\hline Factor & Range of relative risk \\
\hline Assessment of feeding 'not good' & $1 \cdot 13-1 \cdot 21$ \\
Assessment of relationship 'not good' & $1 \cdot 29-1 \cdot 43$ \\
No breast feeding & $1 \cdot 30-1 \cdot 46$ \\
Father's occupation category 'low' & $1 \cdot 18-1 \cdot 28$ \\
Birthweight less than 2500 g & $1 \cdot 10-1 \cdot 15$ \\
Baby 'not well' & $2 \cdot 03-2 \cdot 45$ \\
\hline
\end{tabular}

and maximum predicted relative risks are $6.1 \%$ and $40.7 \%$ corresponding to scores of 0 and 25 ; for non-Asians these risks are $5.5 \%$ and $40.7 \%$ corresponding to scores of 1 and 25 . Thus for a non-Asian child whose only risk factor is birthweight $<2500 \mathrm{~g}$ the risk of admission is $5.5 \times 1.10$-that is roughly $5.7 \%$. A non-Asian child to whom all risk factors except low birthweight apply has a predicted risk $40 \cdot 7 / 1 \cdot 15$ - that is roughly $35 \%$.

\section{References}

1 Emery J, Carpenter RG. Clinical aspects of the Sheffield prospective study of children at possibly increased risk. In: SIDS 1974. Proceedings of Francis E Camps International Symposium on Sudden and Unexpected Deaths in Infancy; Canadian Foundation for the Study of Infant Deaths, 1975: 97-106.

2 Cullinan TR, Treuherz J. 'Born in east London 19791980 ': available from authors' department.

3 Cullinan TR, Treuherz J. 'Ill in east London': available from authors' department.

4 Cullinan TR, Saunders DI, Treuherz J. 'Determinants of infant feeding practice in east London'. Hum Nutr Appl Nutr 1982; 36A: 281-6.

5 Feldstein MS, Butler NR. 'Analysis of factors affecting perinatal mortality-a multivariate statistical approach'. Br J Prev Soc Med 1965; 19: 128-34.

6 Feldstein MS. 'A method of evaluating perinatal mortality risk'. Br J Prev Soc Med 1965; 19: 135-9.

7 Feldstein MS. 'A binary variable multiple regression method of analysing factors affecting perinatal mortality and other outcomes of pregnancy'. $J \boldsymbol{R}$ Statistical Soc $A$ 1966; 129: 61-73.

8 Winter ST, Lilos P. 'Prediction of hospitalization during infancy: scoring the risk of admission'. Pediatrics 1974; 53: 716-20.

9 Carpenter RG, Emery JL. 'Final results of study of infants at risk of sudden death'. Nature $1977 ; 268: 724-5$.

10 Carpenter RG, Gardner A, McWeeny PM, Emery JL. 'Multistage scoring system for identifying infants at risk of unexpected death'. Arch Dis Child 1977;52: 606-12.

11 Carpenter RG, Gardner A, Pursall E, McWeeny PM, Emery JL. 'Identification of some infants at immediate risk of dying unexpectedly and justifying intensive study'. Lancet 1979 ; ii : $343-6$.

12 Carpenter RG. 'Scoring to provide risk-related primary health care. Evaluation and up-dating during use'. $J R$ Statistical Soc A 1983; 146: 1-32.

13 Bishop YMM, Fienberg SE, Holland PW. Discrete multivariate analysis: theory and practice. Cambridge: MIT Press, 1975.

14 Cox DR. The analysis of binary data. New York. Methuen, 1970.

15 O'Muircheartaigh CA, Payne C. The analysis of survey data. Vol 2. Model fitting. New York. Wiley, 1975.

16 Goodman LA. 'The analysis of multidimensional tables: stepwise procedures and direct estimation methods for building models for multiple classification. Technometrics 1971 ; 13: 33-61.

17 Cullinan TR, Saunders DI. Predicting and preventing infant illness in east London-an analysis of social factors associated with hospital admission: available authors' department.

Correspondence to Dr D I Saunders, Department of Computer Science and Statistics, Queen Mary College, Mile End Road, London E1 4NS.

Received 14 February 1983 